\title{
Cervical Vertebral Compressive Myelopathy associated with articular processes osteoarthritis in three horses
}

\author{
Mohammed Adam', Corinna Arnold', Katharina Ehlers', Nicole Graneß', Albrecht Uhlig', Stefan Recknagel', Kerstin Gerlach² \\ and Gerald F. Schusser? \\ ${ }^{1}$ Large Animal Medicine Department \\ 2 Large Animal Clinic for Surgery, Faculty of Veterinary Medicine, University of Leipzig, An den Tierkliniken 11, 04103 Leipzig, Germany
}

\begin{abstract}
Summary: Cervical vertebral compressive myelopathy is a neuropathy resulting in ataxia in horses. Three horses with different signs of incoordination were presented for further evaluation. A five-year-old gelding with a long history of abnormal head and neck carriage, a six-yearold gelding with a history of previous neurological episodes and a two-day history of acute episodes of walking difficulties, and a sixteenyear-old mare with a one-month history of left fore-limb ataxia were diagnosed with osteoarthritis of the facet joints of the caudal cervical vertebrae. Lateral radiographs of caudal cervical vertebrae confirmed osteoarthritis of the articular processes. Radiographic changes, such as enlargement of the articular process joint, periarticular new bone and reduction or narrowing of the intervertebral foramen, were observed in all three cases. Cervical vertebral compressive myelopathy should be considered in ataxic horses with normal laboratory findings.
\end{abstract}

Keywords: horse / CVCM / articular process / osteoarthritis / myelopathy

\begin{abstract}
Zervikale Rückenmarkskompression in Verbindung mit Osteoarthritis des Gelenkfortsatzes bei 3 Pferden
Die zervikale Rückenmarkkompression des Pferdes ist eine durch Ataxie gekennzeichnete Myelopathie. Dem Artikel liegen drei Pferde mit unterschiedlichen Bewegungsstörungen zugrunde, die zur weiteren Diagnostik in der Klinik vorgestellt wurden. Ein 5-jähriger Wallach mit gesenkter Kopf-Hals-Haltung seit sechs Monaten, ein 6-jähriger Wallach mit rechtseitiger Kopf-Hals-Haltung und Ataxie seit vier Monaten und eine 16-jährige Stute mit kontinuierlichem Scharren mit dem linken Vorderbein wurden einer neurologischen Untersuchungen unterzogen. Aufgrund der Schmerzen im kaudalen Halsbereich, der fehlenden Seitwärtsbewegung im Kopf-Hals-Bereich, der Atrophie der kaudalen Halsmuskulatur und des M. suprascapularis und der Tetraparese wurde ein Röntgen der kaudale Halswirbelsäule angefertigt. Die laterolateralen Röntgenaufnahmen ergaben sklerotische und unregelmäßige Facettengelenke von C6 und C7 und Einengungen der Foramina intervertebralia. Die Therapie bestand in der Aufstallung ohne Reiten über sechs Monate. Nur ein Pferd wurde nach dieser Rehabilitationszeit wieder im Freizeitreiten eingesetzt.
\end{abstract}

Schlüsselwörter: Pferd / zervikale Malformation / Facettengelenke / Osteoarthritis / Rückenmarkskompression

Citation: Adam M., Arnold C., Ehlers K., Graneß N., Uhlig A., Recknagel S., Gerlach K., Schusser G. F. (2016) Cervical Vertebral Compressive Myelopathy associated with articular processes osteoarthritis in three horses. Pferdeheilkunde 32, 249-253

Correspondence: Prof. Gerald F. Schusser, Universität Leipzig, Medizinische Tierklinik, An den Tierkliniken 11, 04103 Leipzig, e-mail: schusser@vetmed.uni-leipzig.de

\section{Introduction}

Cervical vertebral compressive myelopathy (CVCM) is a neurological disease characterised by incoordination and weakness of limbs (ataxia), due to spinal cord compression anywhere between the first cervical $(\mathrm{C} 1)$ and the first thoracic vertebra (Th1) (Nout and Reed 2003, Levine et al. 2007and 2008, Rush 2009). Cervical vertebral compressive myelopathy has been classified into two forms, dynamic and static. Dynamic compression occurs during neck movement, particularly ventral flexion, and usually affects young horses (8-18 months) at the levels of $\mathrm{C} 3-\mathrm{C} 4$ and $\mathrm{C} 4-\mathrm{C} 5$. Static compression is characterised by continuous spinal cord compression regardless of neck position, and is commonly seen in older horses (1-4 and 5-10 years) at caudal cervical vertebrae (C5-Th1) (Nout and Reed 2003, Rush 2009).

Cervical vertebral compressive myelopathy has been reported to be more common in Thoroughbreds (Powers et al. 1986, Levine et al. 2008) and in geldings and stallions (Powers et al. 1986, Gerber et al. 1989, Levine et al. 2007 and 2008). Dynamic compression at C3-C7 usually results in gait defi- cits (grade $0=$ normal gait, $1=$ mild, $2=$ moderate, $3=$ obvious with exaggeration on a slope, $4=$ nearly falling during movement, $5=$ recumbent), characterised by weakness resulting in stumbling or toe-dragging of all four limbs, although they are more obvious in the hind-limbs (Reed and Andrews 2010). Neurological deficits of the fore-limbs are commonly seen in horses with static compression due to brachial intumescence lesions (Seino 2010). Diagnosis of CVCM is based on clinical history and clinical examination. Neurological examination is very important to determine the neurological deficits and to localise the affected part of nervous system (Furr and Reed 2008, Tipold 2009).

Osteoarthritis of the cervical vertebral articular processes has been described as one of the main causes of CVCM in horses (Nout and Reed 2003, Withers et al. 2009). Radiographic changes of the articular process osteoarthritis include osteophytosis, alterations of the articular surface and sclerosis of subchondral bone (Dimock and Puchalski 2010). The aim of the current report was to describe the neurological deficits and radiographic signs of caudal CVCM associated with articular process joint osteoarthritis in three older horses. 


\section{Case 1}

A five-year-old, $525 \mathrm{~kg}$ body weight, Warmblood gelding was examined for a history of abnormal head and neck posture over one and a half years. The gelding had been received meloxicam (Metacam ${ }^{\circledR}$, Boehringer, Ingelheim, Germany) without improvement. The gelding had been vaccinated against tetanus, influenza and equine herpesvirus types 1, 4 $(E H V-1,4)$ and deworming was performed. On admission, the gelding had a normal rectal temperature $\left(37.4^{\circ} \mathrm{C}\right)$, heart rate (32 beats/min) and respiratory rate (16 breaths/min). All clinicopathological parameters, including creatine kinase activity, were within normal limits. Based on the history, the head was held lower than the withers when viewed from the side. The neurological examination revealed gait abnormality $(2 / 5)$ with weakness (paresis) and hypometria in the hindlimbs. The horse had pain in the caudal neck and cranial region of the shoulder of the left side based on palpation. Cerebral nerves, trunk reflexes and perineal reflex were normal. Based on the hypometria in the hind-limbs and the pain in the caudal region of the neck, the caudal cervical vertebrae were radiographed. Cervical lateral and oblique radiographs showed enlarged and irregular facets of the articular joints and narrowing of the intervertebral foramen between C6 and C7 (Fig. 1). The left facet of C6 appeared longer and sclerotic with an irregular edge. Osteoarthritis of the left facet joint between $\mathrm{C} 6$ and $\mathrm{C} 7$ was diagnosed. The minimum intervertebral and intravertebral diameter ratios of $\mathrm{C} 3 / \mathrm{C} 4$ to C6/C7, resp. C3 to C7, were greater than 0.48 (Hahn et al. 2008). The abnormal lower head posture with pain in the caudal neck area on the left hand side and the gait abnormality (ataxia in the hind-limbs) did not improve within six months after discharge.

\section{Case 2}

A six-year-old, $676 \mathrm{~kg}$ body weight, Warmblood gelding was admitted with a history of ataxia for further investigation. The gelding had shown acute episodic ataxia one and a half years before admission, and another episode had occurred three to four months ago. The gelding had been vaccinated against tetanus, influenza and equine herpesvirus 1, 4 (EHV$1,4)$. Oral deworming using commercially available prepa- rations had been performed two to three times per year. At presentation, the gelding was normothermic $\left(37.6^{\circ} \mathrm{C}\right)$, tachycardic (48 beats/min) and tachypneic (26 breaths/min). All clinicopathological parameters, including creatine kinase activity, were within normal limits. The gelding had slightly right-sided neck posture, staggering gait, dragging hindlimbs during walking with exaggerated hind-limb ataxia and hypermetria in the fore-limbs when the horse walked with an elevated head (gait deficit 3/5). A slightly weak response to the right-side tail-pull test and no cerebral nerve deficits were detected. The palpation of the head, neck, trunk, fore-limbs and hind-limbs revealed no signs of pain. The panniculus and flexor reflexes of all four limbs and the perineal reflex were normal. Based on the tetra-ataxia and tetraparesis, vertebral lesions in the caudal cervical vertebrae were considered. Radiographic findings revealed extensively enlarged facets of the joints and narrowed intervertebral foramen between $\mathrm{C} 6$ and C7 (Fig. 2). Osteoarthritis of the facet joints between C6 and $\mathrm{C} 7$ was diagnosed. The minimum intervertebral and intravertebral diameter ratios of C3/C4-C6/C7, resp. C3-C7, were greater than 0.48 . The head posture and the gait abnormality improved during stall rest and turning out on a small paddock within six months after discharge. After this, the gelding has been used for short-term leisure riding.

\section{Case 3}

A sixteen-year-old, $528 \mathrm{~kg}$ body weight, Warmblood mare was referred to the large animal hospital for evaluation of a four-week history of left fore-limb pawing with worn hoof and weight loss. Before referral, the mare had been administrated phenylbutazone, but no improvement was observed. Physical examination revealed normal body temperature $\left(37.2^{\circ} \mathrm{C}\right)$, heart rate (40 beats/min) and slight tachypnea (20 breaths/min). The mare was reluctant to move, with left forelimb pawing in the stall and during examination. A painful swelling dorsal to the left shoulder was palpated. Laboratory examination revealed leukocytosis $115.3 \mathrm{G} / \mathrm{l}$; normal range: 4.4-12 G/I), characterised by segmented neutrophilia (12.85 $\mathrm{G} / \mathrm{l}$; normal range: $2-6.9 \mathrm{G} / \mathrm{l})$. Only the creatine kinase activity was elevated at $564 \mathrm{U} / \mathrm{I}$ (normal range 146-354 U/I) in clinicopathological tests (Köller et al. 2014). Serum electrophoresis showed normal protein concentrations. Based on the

Fig. 1 Case 1: There is a slightly oblique orientation of the picture and cranial is to the left. The articular process joints are extensively enlarged and irregular facets are between $\mathrm{C} 6$ and $\mathrm{C} 7$ (white arrow). The left facet of C6 appeared longer and was sclerotic with an irregular edge. The intervertebral foramen is completely obliterated and the ventral aspect of the articulation extends to the vertebral body (black arrow) with malalignment of the floor.

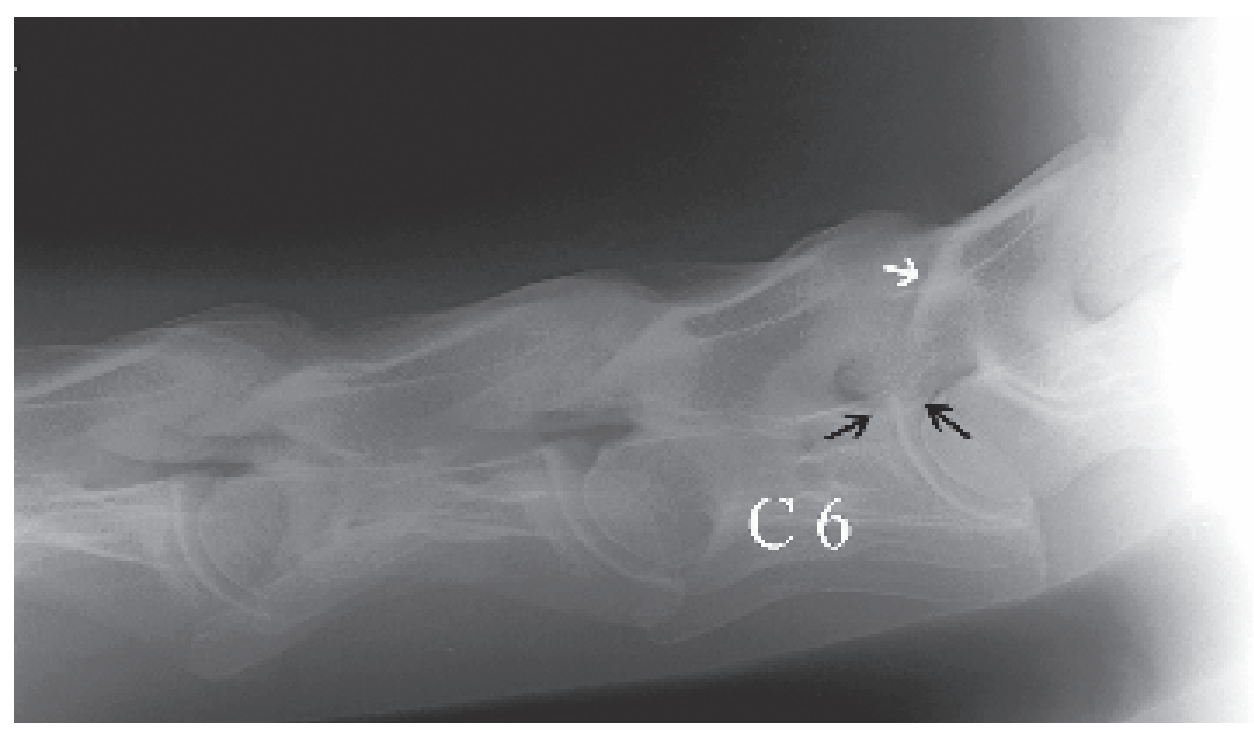




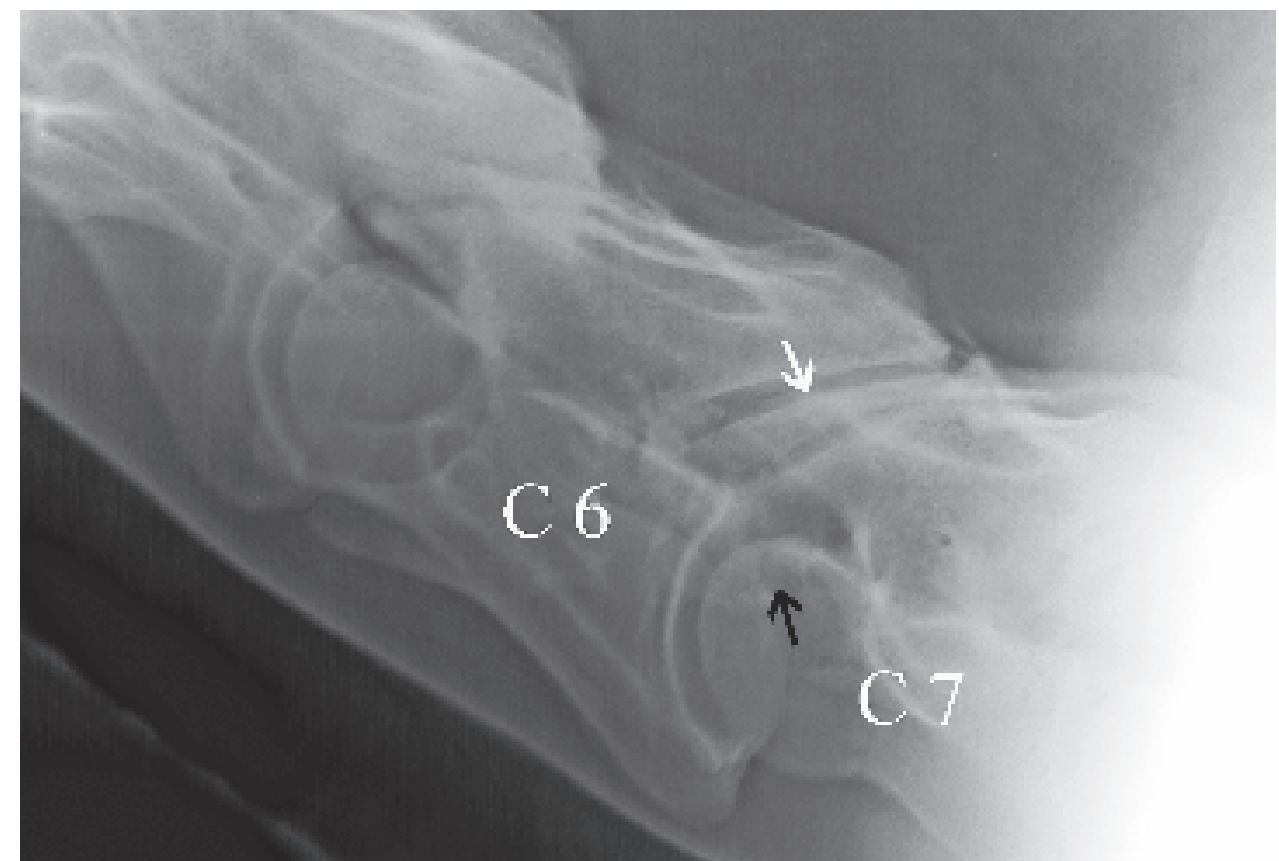

Fig. 2 Lateral radiograph of the caudal cervical spine of case 2 demonstrates osteoarthritis of the articular process between $\mathrm{C} 6$ and C7. There is extensive modelling of the articular facets of $\mathrm{C} 6$ and C7. The joint is enlarged and has an irregular surface and subchondral sclerosis (white arrow). The intervertebral foramen is closed by a radiopaque structure (black arrows). Cranial is to the left.

administration of phenylbutazone, a gastroscopic examination was performed and large multifocal pyloric ulcers (4/4) and decreased pyloric motility were detected. Gastric biopsies showed chronic gastritis. Neurological evaluation revealed a grade 3 of 5 gait deficit with ataxia on the left fore-limb and atrophy of the left caudal cervical, supraspinatus and infraspinatus muscles. The behaviour was characterised by pawing with the left fore-limb continuously in the stall during daytime. The flexion of the neck to the left side was normal ranging through the joint of the shoulder, but to the right side, it was incomplete and the horse had the tendency to fall in that direction. The swollen left shoulder cartilage region was painful and pain was detected from the left caudal cervical region to the left aspect of the thoracic body wall. The mare tended to collapse onto the hind-limbs in the backward walking test. The mare did not resist tail-pull on either side of the hind-limbs. The flexor reflex of the left fore-limb was poor. Sideways hopping by raising the right fore-limb was not possible. No cerebral nerve deficits were detected, and trunk reflexes and perineal reflex were normal. The neurological examinations were very important to localise the lesion in the caudal region of the cervical spinal cord and determine which part of the neck should be radiographed. Based on the neck pain, weakness in the hind-limbs, the poor flexor reflex of the left fore-limb, the difficulties of backing-up and the muscle atrophy described, the lesion could be caused by a cervical spinal cord compression between $\mathrm{C} 6$ and Th 1 .

Radiographic examination revealed an enlargement of facets of the joints between $\mathrm{C} 6$ and $\mathrm{C} 7$ and between $\mathrm{C} 7$ and Th 1 . The joints were sclerotic and the intervertebral foramen was narrow between $\mathrm{C} 6$ and $\mathrm{C} 7$, and completely ankylosed between $\mathrm{C} 7$ and Th1 (Fig. 3). The minimum intervertebral and intravertebral diameter ratios of C5/C6-C6/C7, resp. C5C7, were greater than 0.48 . Based on radiographic and gastroscopic changes, a diagnosis of CVCM, due to chronic articular process osteoarthritis of the caudal cervical vertebrae, and gastric ulcers (grade 4 of 4) was made. Due to the continuous pawing with the left fore-limb, the left radial nerve was thought to be injured at the level of the narrowed intervertebral foramen (C6/C7) and could induce paraesthesia. During hospitalisation, the mare was administered phenylbu-

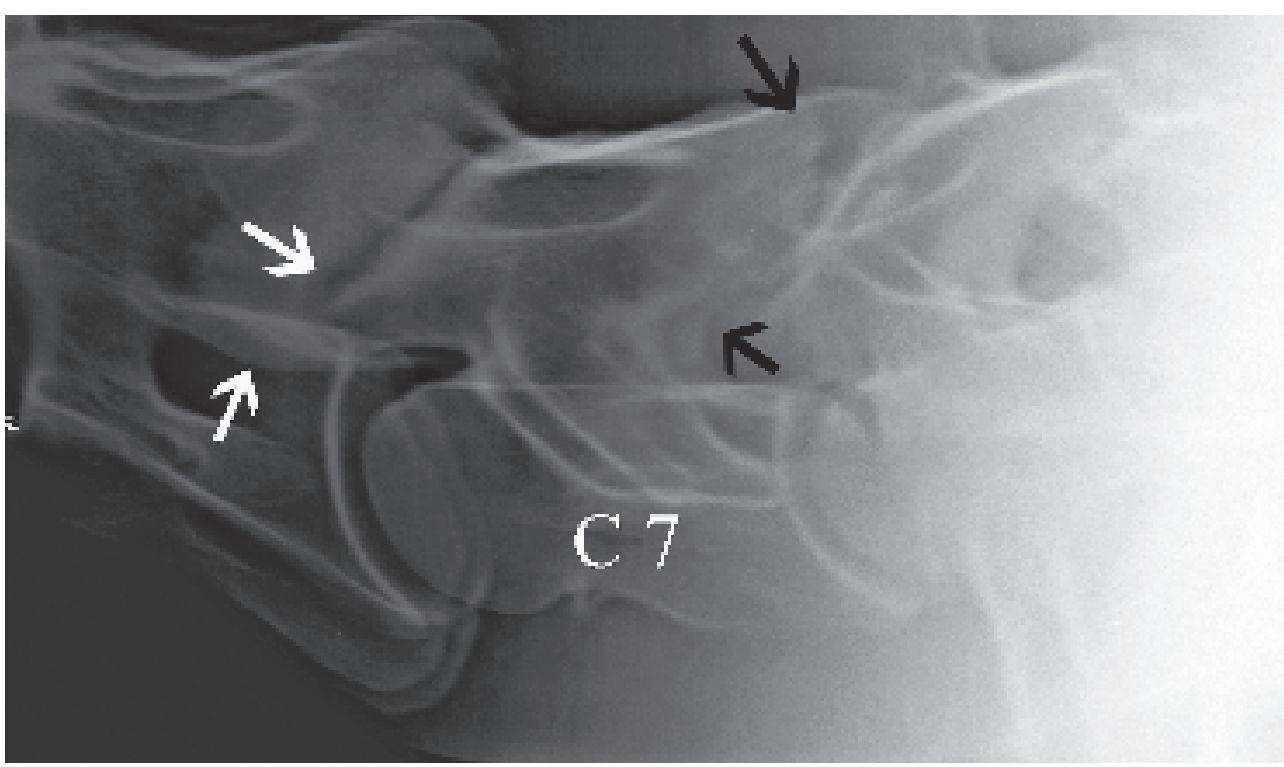

Fig. 3 Lateral and oblique radiograph of the caudal cervical spine of case 3 shows enlarged and irregular facets of the articular process between C6 and C7 (white arrows) and massive enlargement of the synovial articulations between $\mathrm{C} 7$ and Th1 (black arrows). The joints are sclerotic and the intervertebral foramina are narrow between C6 and C7 and completely closed between C7 and Th1. Cranial is to the left. 
tazone (Butasan ${ }^{\circledR}$, Selectavet, Holzolling, Germany; $2 \mathrm{mg} / \mathrm{kg}$ PO q12 hrs for 10 days) and omeprazole (Pepticure ${ }^{\circledR}$, Bayer, Leverkusen, Germany; $4 \mathrm{mg} / \mathrm{kg}$ PO q24 hrs for 10 days). The mare gained weight but she was not able to be used for leisure riding for six months after discharge from the animal hospital.

\section{Discussion}

This report describes equine spinal ataxia with spinal cord compression thought to be secondary to cervical articular process osteoarthritis in three horses, in addition to a lesion of the suprascapular nerve in the sixteen-year-old mare. Neurological examination represents a very important part of the CVCM investigation. Neurological findings, such as bilateral shoulder muscle tone deficits, pain in the caudal neck and cranial shoulder regions, and hind-limb hypometria; as described in case 1. Ataxia of all four limbs, lateral deviation of the neck, hypermetria of the fore-limbs and weak response to sway test were clinically found in case 2 . Unilateral atrophy of shoulder muscles and hyperaesthesia (pain) of neck, shoulder and thoracic regions were detected in case 3. The CVCM could be localised between C5-C6, C6-C7 or C7-Th1. Horses presented with no neurological signs, neck stiffness, abnormal head and neck posture or fore-limb ataxia, can have a vertebral lesion between C5-C6 or C6-C7 (Down and Henson 2009). Paretic horses have a low limb swing phase during the stride, stumble, weak response to sway test, knuckling in downhill walking and difficulties in the fore-limbs hop test. Hypermetria is characterised by excessive limb and joint movements and is associated with cerebellar or spinal cord diseases. Hypometric horses have limb stiffness and reduced joint flexion (Furr and Reed 2008). The present study shows that horses with caudal cervical articular process osteoarthritis can present a variety of clinical signs, ranging from abnormal posture of the head and neck to staggering gait. All three cases were more than five years old, had no recorded history of head and neck trauma and the clinical signs had developed over a long period. Other studies have reported that horse affected may develop acute onset of ataxia associated with history of trauma, however, the horse might be slightly ataxic prior to trauma, and the trauma exaggerated these neurological signs (Nout and Reed 2003). Chronic signs can be developed over weeks or months in older horses (Wagner et al. 1987, Nout and Reed 2003).

Previous studies stated that CVCM can be caused by osteoarthritis, however, the main cause of this abnormality is unknown (Levine et al. 2007), and 50\% of asymptomatic adult horses have unilateral or bilateral surface changes of the facet joints and irregular enlargement of the articular processes of the caudal cervical vertebrae (Down and Henson 2009, Dyson 2011). The diagnosis cannot be made upon radiographic findings alone because similar findings are described in horses without clinical symptoms (Down and Henson 2009). Therefore, the definitive diagnosis has to be validated based on clinical findings.

In this study, the diagnosis of CVCM in the three horses was based on neurological examinations and radiographic lesions of the caudal cervical vertebrae. Haematological and serum biochemical examinations were mostly within normal limits
(Nout and Reed 2003), analysis of cerebrospinal fluid (CSF) collected from lumbosacral space was normal, although CSF protein concentrations in some affected horses described in the literature were slightly increased up to $1580 \mathrm{mg} / \mathrm{l}$ (normal value; 249-620 mg/l) (Powers et al. 1986, Eckhoff et al. 2006). The most common vertebral lesion detected on the lateral radiographs was degenerative joint disease, characterised by osteoarthrosis, osteochondrosis and enlargement of the periarticular soft tissue of the facet joints.

A previous pathological study suggested that osteoarthritic lesions of the articular process joints, such as osteochondrosis and osteophytosis, lead to instability of facet joints, which results in spinal compression (Powers et al. 1986). In case 1, radiographic findings matched perfectly with the neurological deficits, however, the arthropathy of the left facet joint between $\mathrm{C} 6$ and $\mathrm{C} 7$ could also be associated with clinical neck pain. In cases 2 and 3 , the abnormal head and neck posture respectively, and limited right-sided neck flexion were caused by neck pain. This in-turn was likely due to intervertebral arthropathy (sclerotic facets of the articular processes) and/or compression of intervertebral nerves (suprascapular nerve, caudal cervical spinal nerves). The neck flexion test has important value in detecting abnormalities of intervertebral mobility (Wessum 2011). Pawing and resting of the left forelimb in case 3 may indicate pain or paraesthesia, particularly as the mare refused to bear any weight on it; considering the swelling of the region and atrophy of the left caudal cervical, supraspinatus and infraspinatus muscles, it could be due to trauma of the left side. However, neurapraxis or axonotmesis of the caudal cervical spinal nerves and suprascapular nerve induced by narrow intervertebral foramen could also generate muscle atrophy. Mayhew (1989) has stated that osteoarthropathies of the cervical vertebrae are associated with forelimb gait abnormalities due to compressive radiculopathy, dural irritation or painful arthrosis. The same report has explained a case of a two-year-old Thoroughbred colt with left brachial injury, which could not bear any weight on the left fore-limb and had hypalgesia, and another case of a Thoroughbred filly which had atrophy of the shoulder muscles due to suprascapular nerve entrapment with fibrous tissue after injury. Case 3 had severe pyloric ulcers, which may be due to decreased food intake, especially hay, which resulted in delayed gastric emptying and subsequent pyloric ulcers. The latter could have been worsened by pre-admission use of phenylbutazone. The mare was treated with omeprazole to prevent gastric ulcers.

In conclusion, different clinical signs of the caudal CVCM can be developed in a chronic form in older horses. Therefore the saggital diameters of C2 to C7 have to be measured and the articular processes of $\mathrm{C} 6$ to Th 1 have to be examined for verifying cervical vertebral malformation with compression of the spinal cord and/or intervertebral nerves. All three cases had this vertebral facet joint syndrome described. A very important factor for treatment is rehabilitation with stall rest or on a small paddock or pasture for a period of at least three months. Nonsteroidal anti-inflammatory drugs (e.g. $0.5 \mathrm{mg}$ flunixin meglumine $/ \mathrm{kg} \mathrm{bw} / \mathrm{d}$ or $2 \mathrm{mg}$ phenylbutazone $/ \mathrm{kg} \mathrm{bw} / \mathrm{d}$ for two to four weeks orally) reduce local muscle spasm. Local administration of, for example, triamcinolone $(10 \mathrm{mg})$ into the articular process joints may help reduce inflammation. Suspected horses with normal laboratory findings should be neurologi- 
cally examined to localize the vertebral lesions, which can be confirmed by using cervical vertebral radiography.

\section{References}

Dimock A., Puchalski S. (2010) Cervical radiology. Equine Vet. Educ. 22, 83-87

Down S., Henson F. (2009) Radiographic retrospective study of the caudal cervical articular process joints in the horse. Equine Vet. J. $41,518-524$

Dyson S. (2011) The cervical spine and soft tissues of the neck. In: Diagnosis and Management of Lameness in the Horse. 2nd ed. Ross M., Dyson S. (eds.), Elsevier Saunders, Maryland Heights, MO, USA, 606-616

Eckhoff A., Reiber H., Kirbach H., Uhlig A., Schusser G. F. (2006) Cerebrospinal fluid analysis in equine Borna disease - a new diagnostic approach to measure intrathecal immune response. Vet. Med. Austria 93, 235-243

Furr M., Reed S. (2008) Neurological examination. In: Equine Neurology. Furr M., Reed S. (eds.), Blackwell publishing, Ames, IA, USA, $65-76$

Gerber H., Ueltschi G., Diehl M., Schatzmann U., Straub R. (1989) Untersuchungen an der Halswirbelsäule des Pferdes - eine klinischradiologische Studie. Schweiz. Arch. Tierheilk. 131, 311 1-321

Hahn C. N., Handel I., Green S. L., Bronsvoort M. B., Mayhew I. G. (2008) Assessment of the utility of using intra- and intervertebral minimum sagittal diameter ratios in the diagnosis of cervical vertebral malformation in horses. Vet. Radiol. Ultrasound 49, 1-6

Köller G., Gieseler T., Schusser G. (2014) Hematology and serum biochemistry reference ranges of horses of different breeds and age measured with newest clinicopahological methods. Pferdeheilkunde 30, 381-393

Levine J., Adam E., MacKay R., Walker M., Frederick J., Cohen N. (2007) Confirmed and presumptive cervical vertebral compressive myelopathy in older horses: a retrospective study (1992-2004). J. Vet. Intern. Med. 21, 812-819

Levine J., Ngheim P., Levine G., Cohen N. (2008) Associations of sex, breed, and age with cervical vertebral compressive myelopathy in horses: 811 cases (1974-2007). J. Am. Vet. Med. Assoc. 233, 1453-1458

Mayhew I. (1989) Paresis and paralysis of one limb. In: Large Animal Neurology: A Handbook for Veterinary Clinicians. Mayhew I. (ed.), Lea \& Febiger, Philadelphia, PA, USA, 335-347

Nout Y., Reed S. (2003) Cervical vertebral stenotic myelopathy. Equine Vet. Educ. 15, 212-223

Powers B., Stashak T., Nixon A., Yovich J., Norrdin R. (1986) Pathology of the vertebral column of horses with cervical static stenosis. Vet. Pathol. 23, 392-399

Reed S., Andrews F. M. (2010) Disorders of the neurologic system. In: Equine Internal Medicine. 3rd ed. Reed S, Bayly W, Sellon D et al. (ed.) Saunders, St. Louis, USA, 545-681

Rush B. (2009) Cervical stenotic myelopathy. In: Large Animal Internal Medicine. 4th ed. Smith B. (ed.), Mosby Elsevier, Maryland Heights, MO, USA, 1067-1072

Seino K. (2010) Spinal ataxia. In: Equine Internal Medicine. 3rd ed. Reed S., Bayly W., Sellon D. (eds.), Elsevier Saunders, Maryland Heights, MO, USA, 134-138

Tipold A. (2009) Neurologischer Untersuchungsgang. In: Klinische Propädeutik der Haus- und Heimtiere. 7th ed. Baumgartner W. (ed.), Parey, Medizinverlage Stuttgart, Germany, 284-317

Wagner P., Grant B., Reed S. (1987) Cervical vertebral malformation. Vet. Clin. N. Am. Equine Pract. 3, 385-396

Wessum R. (2011) Lameness associated with the axial skeleton. In: Adams and Stashak's Lameness in Horses. 6th ed. Baxter G. (ed.), Wiley-Blackwell, Chichester, West Sussex, UK, 833-869

Withers J., Voûte L., Hammond G., Lischer C. (2009) Radiographic anatomy of the articular process joints of the caudal cervical vertebrae in the horse on lateral and oblique projections. Equine Vet. J. $41,895-902$ 